\title{
CERCOPÍDEOS NO RIO GRANDE DO SUL: ISCHNORHININI (HOMOPTERA)*
}

\author{
Gervásio Silva Carvalho**
}

\begin{abstract}
Four spittlebugs belonging to the Ischnorhinini (Hom., Auchenorhyncha), occurring in Rio Grande do Sul (Brazil), with respective synonymy and distribution, are characterized in the present paper.

Also keys for the distinction of Brazilian tribes, genera and species are presented.
\end{abstract}

\section{INTRODUÇÃO}

A família Cercopidae Westwood, 1838 inclui insetos vulgarmente referidos como cigarrinhas. Algumas espécies constituem verdadeiras pragas de gramíneas. A necessidade do conhecimento das espécies que ocorrem no Rio Grande do Sul objetivou este trabalho.

Da espécies até então conhecidas para o Estado, incluídas em Ischnorhinini, cumpre citar Sphenoclypeana consanguinea (Distant, 1909) e $S$. parana (Distant, 1909).

A fauna cercopidológica da região neotropical começou a ser conhecida com os trabalhos de Walker, que em 1851 descreveu várias espécies da América do Sul e Brasil, entre elas Sphenorhina ocellata.

Distant (1909) descreveu vários gêneros, entre eles Neosphenorhina, além de várias espécies deste e de outros gêneros, como Tamaspis para$n a, T$. brasiliensis e $T$. consanguinea, esta do Rio Grande do Sul. Transferiu $S$. ocellata para Neosphenorhina.

Nast (1951), revisando Cercopinae neotropicais, principalmente do gênero Tomaspis, descreveu gêneros novos, entre eles Guarania, colocando neste as espécies $T$. consanguinea e $T$. brasiliensis, entre outras.

Lallemand \& Synave (1952) publicaram uma nota sobre os homópteros depositados no Instituto Real de Ciências Naturais da Bélgica, onde descreveram o gênero Sphenoclypeana, incluindo nele as espécies $T$. pa-

* Trabalho apresentado no IX Congresso Brasileiro de Zoologia - Porto Alegre - RS.

** Instituto de Biociências, Pontifícia Universidade Católica Porto Alegre - RS, C. P. 1429 - CEP. 90000. 
rana e $T$. brasiliensis.

Fennah (1968) publicou revisão dos cercopídeos do Novo Mundo, estabelecendo a sinonimia do gênero Sphenoclypeana com Guarania.

Nast (1975) publicou artigo sobre cercopídeos neotropicais onde, no final da publicação, esclarece que o gênero Guarania Nast, 1951 (outubro), já se encontrava pré-ocupado por Guarania Carvalho \& China, 1951 (maio), ficando as espécies deste gênero enquadradas em Sphenoclypeana, que, embora baseados em diferentes espécies tipo, tratam-se de sinônimos, segundo Fennah (1968).

\section{MATERIAL \& MÉTODOS}

O material examinado, num total de 51 exemplares, encontra-se depositado nas coleções das seguintes Instituições: Embrapa-Pelotas (UEPAE); Faculdade de Agronomia da UFRGS-Setor de Entomologia Porto Alegre (FASE); Faculdade de Agronomia da UFSM-Santa Maia (UFSM); Instituto de Biociências da PUC-RS-Núcleo de EntomologiaPorto Alegre (PUC); IPAGRO-Porto Alegre (IPA); Museu Anchietano de Ciência-Porto Alegre (MAPA); Museu de Ciências Naturais da Fundação Zoobotânica-Porto Alegre (MCN); e Universidade Federal de Pelotas - Pelotas (UFP); bem como em uma coleção particular do Eng. Agr. $\quad$ Cesar Augusto Trois (CAT).

O reconhecimento das espécies foi feito com uso de descrições originais, redescrições e chaves dicotômicas com base na bibliografia atinente ao grupo.

As referências bibliográficas até 1960 poderão ser tomadas de Metcalf, Z. P. (1960) "A bibliography of the Cercopoidea (Homoptera: Auchenorhyncha)" (State College of the University of North Carolina, Raleigh, N. C., U.S.A.).

Nos resultados serão citadas as espécies encontradas no Rio Grande do Sul, com respectiva sinonímia, distribuição, caracterização e material examinado.

\section{RESULTADOS}

A familia Cercopidae, segundo Fennah (1968), está constituída de duas subfamilias: Cercopinae, geralmente com um espinho lateral na postíbia, com espécies distribuidas no Velho Mundo, e Tomaspidinae, com dois espinhos na postíbia e com espécies do Novo Mundo.

\section{SUBFAMÍLIA TOMASPIDINAE}

Fennah (1968) dividiu esta subfamília em quatro tribos, conforme chave abaixo: 
1. Posclípeo fortemente comprimido, com lados quase completamente achatados, com uma crista oblíqua, bordeada acima por ranhuras, estendendo-se, no ângulo de baixo da superfície lateral do posclípeo, em direção a placa mandibular ............................. Ischnorhinini Posclípeo não fortemente comprimido e sem uma crista oblíqua bordeada acima por ranhuras .......................................... 2

2. Posclípeo com um sulco longitudinal mediano, iniciando-se desde a margem anterior da cabeça, ou com uma fraca depressão, bordeadas por duas pequenas eminências, no ângulo inferior; ou tégmina com somente uma única linha de veias transversais ....................... 3 Posclípeo sem um sulco mediano ou duas pequenas eminências no ângulo inferior; tégmina com mais que uma única linha de veias transversais ............................................... Tomaspidini

3. Posclípeo comprimido, não dilatado e com área mediana estreita; se não, então o $3^{\circ}$. artículo antenal é levemente cônico ou ovóide e a tíbia posterior apresenta não menos que 11 espinhos apicais . Hyboscartini Posclípeo não comprimido, 3 . artículo antenal subgloboso, tão largo como longo; tíbia posterior com menos de 11 espinhos apicais.

Neaenini

\section{TRIBO ISCHNORHININI SCHMIDT, 1920}

Compreende nove gêneros, dos quais dois incluem espécies encontradas no Rio Grande do Sul, podendo ser separados pela chave a seguir:

1. Artículo basal do tarso posterior com cerca de seis espinhos apicais; rostro com ápice sobrepondo a coxa posterior; veia Cul na asa gradual e ligeiramente alargada na base ................. Ischnorhina Stal Artículo basal do tarso posterior com nove a 14 espinhos apicais .... 2

2. Tíbia posterior com somente um espinho lateral

Laccogrypota Schmidt

Tíbia posterior com dois espinhos laterais, o basal pode ser fraco ou diminuto ........................................................ 3

3. Tíbia posterior com um muito pequeno e inconspícuo espinho lateral na base Typeschata Schmidt

Tíbia posterior com dois espinhos laterais bem desenvolvidos.........4

4. Rostro atingindo somente até a coxa mediana ....................... 5

Rostro atingindo a coxa posterior ou ultrapassando-a ................ 6

5. Posclípeo com uma pequena fenda no ápice da carena mediana, os lobos de tal modo formados, ligeiramente inclinados para fora

Schistogonia Stal

Posclípeo não fendido no ápice da carena mediana

Sphenoclypeana Lallemand

6. Veia Cul na asa não ou só gradualmente alargada em direção a base .. 
Veia Cul na asa um pouco abrupta e marcadamente alargada próximo da base .............................................................. 7

7. Tégmina de comprimento quase 3,5 vezes a sua largura

Homalogrypota Schmidt

Tégmina de comprimento quase 3,0 vezes a sua largura

Baetkia Schmidt

Neophenorhina Distant, 1909

Este gênero está cunstituido por duas espécies, ambas ocorrendo no Brasil, das quais somente uma foi constatada no material examinado. Pode-se distingui-las através da chave abaixo:

1. Tégmina amarelada com uma ampla mancha circular vermelha, circundada de negro, no terço apical N. ocellata

Tégmina com terço basal marron-amarelado, tornando-se vermelha para a extremidade; margem apical bordeada de negro, com mancha alongada, marron, entre as veias $\mathrm{M} \mathrm{e} \mathrm{Cu}$ N. notabilis

Neosphenorhina ocellata (Walker, 1851)

Sphenorhina ocellata Walker, 1851b:693.

Neosphenorhina ocellata; Distant, 1909a:206; Lallemand, 1912a:103 (Pl.4, Figs. 4, 4a), 1949a:163; Metcalf, 1961:80 (cat.); Fennah, 1968:171.

Distribuição: Brasil, Colômbia e Venezuela.

Rio Grande do Sul: Carazinho, Caxias do Sul (Vila Oliva), Salvador do Sul, São Francisco de Paula e São Paulo (sic).

Vermelho brilhante; cabeça e pronoto grosseiramente puncturado e com pubescência amarela; posclípeo extremamente comprimido, formando um ângulo reto de perfil, com carena muito delgada e estrias transversais pouco distintas; rostro negro, vermelho próximo da base; antenas negras. Cabeça e pronoto com pubescência amarela. Tégminas amareladas, longas e estreitas, próximo da extremidade uma ampla mancha circular vermelha, circundada por um círculo negro. Asas menos coloridas, marron pálido na extremidade e ao longo do bordo posterior, veias negras, amarelas na base. Esterno e urosternitos vermelhos. Pernas com coloração geral vermelha, tíbias posteriores com 10 espinhos apicais, tarso posterior com artículo basal portando nove a 12 espinhos apicais.

Medidas: com base em dois machos e 12 fêmeas. 
M ACHOS

19492MCN 5830MAPA Média Média D.P.

$\begin{array}{lrrrrr}\text { Compr. total } & 11,6 & 12,2 & 11,9 & 11,958 & 0,719 \\ \text { Compr. tégmina } & 9,5 & 10,0 & 9,75 & 9,741 & 0,631 \\ \text { Larg. tégmina } & 2,2 & 2,7 & 2,45 & 2,866 & 0,177 \\ \text { Compr. pronoto } & 1,9 & 2,1 & 2,0 & 2,158 & 0,144 \\ \text { Larg. pronoto } & 3,0 & 3,2 & 3,1 & 3,249 & 0,239\end{array}$

Material examinado: 8 $९$ Caxias do Sul (Vila Oliva), 1 \&ão Francisco de Paula e 1 ơ Salvador do Sul - Pe. Buck, leg. (MAPA); 1 O São Paulo - RS - C.R.S., leg., 1 \& Carazinho - ?, 2 ९९ Caxias do Sul - ? (MCN).

\section{Sphenoclypeana Lallemand \& Synave, 1952}

O gênero em questão apresenta no Brasil quatro espécies, que podem ser distinguidas pela chave abaixo:

1. Cabeça, pronoto e escutelo não totalmente sanguíneos ............... 2 Cabeça, pronoto e escutelo totalmente sanguíneos; rostro não ultrapassando a coxa mediana; artículo basal do tarso posterior com 13 espinhos apicais ......................................... . consanguinea

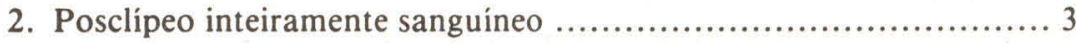
Posclípeo não inteiramente sanguíneo; edeago com um par de espinhos na extremidade, que é alargada ..................... brasiliensis

3. Tégmina de comprimento superior a três vezes a sua largura ............

Tégmina de comprimento três vezes a sua largura S. chapada

Sphenoclypeana brasiliensis (Distant, 1909)

Sphenorhina marginata Walker, 1851b:686 (nec Fabricius).

Tomaspis marginata; Walker, 1858b:175

Tomaspis brasiliensis Distant, 1909a:194; Lallemand, 1912a:91.

Guarania brasiliensis; Nast, 1951b:63 (Figs. 3d, 7).

Sphenoclypeana brasiliensis; Lallemand \& Synave, 1952a:10

(Figs. 4-6); Metcalf, 1961:126 (cat).

Distribuição: Brasil e Paraguai.

Rio Grande do Sul: Cerro Largo.

Corpo e pernas negras, ápice da cabeça, margem lateral e uma listra longitudinal no centro do pronoto e o extremo basal dos urotergitos san- 
guíneos. Posclípeo não totalmente sanguíneo; rostro e antenas negras. Tégminas sanguíneas, margens costal e apical e uma larga listra mediana longitudinal, que ocupa parte do clavo e continua-se até próximo do ápice, negro. Asas fuliginosas. Tíbias posteriores com 17 espinhos apicais, artículo basal do tarso posterior com nove espinhos apicais, cobertos por um denso conjunto de cerdas.

Medidas: com base em um macho e duas fêmeas.

MACHO FÊMEAS

5836MAPA 5835MAPA 5837MAPA Média

$\begin{array}{lrrrr}\text { Compr. total } & 18,0 & 19,5 & 18,2 & 18,85 \\ \text { Compr. tégmina } & 15,2 & 16,8 & 15,3 & 16,05 \\ \text { Larg. tégmina } & 4,9 & 5,2 & 5,5 & 5,25 \\ \text { Compr. pronoto } & 3,3 & 3,5 & 3,5 & 3,5 \\ \text { Larg. pronoto } & 5,5 & 5,7 & 6,0 & 5,85\end{array}$

Material examinado: 1 ơ e 2 $९$ - Cerro Largo - Pe. Buck (MAPA).

Sphenoclypeana consanguinea (Distant, 1909)

Tomaspis consanguinea Distant, 1909a:194; Lallemand, 1912a:92

Guarania consanguinea; Nast, 1951b:59 (Fig. 3a,4); Metcalf, 1961:79 (cat.); Fennah, 1968:171.

Sphenoclypeana consanguinea; Nast, 1975:99.

Distribuição: Argentina (Tucuman) e Brasil (Rio Grande do Sul, Santa Catarina).

Rio Grande do Sul: Estrela, Guaíba, Montenegro (Pareci Novo), Pelotas, Porto Alegre, Restinga Seca, Salvador do Sul, Santa Maria, São Leopoldo, Sapucaia do Sul, Taquarí e Torres.

Cabeça, posclípeo, pronoto, escutelo, tégminas e pernas sanguíneos. Cabeça com duas fossetas laterais; posclípeo forte, central e longitudinalmente carenado, moderadamente comprimido, não terminando em ponto obtuso; antenas de um vermelho escuro, tornando-se mais claras em direção ao último artículo que é negro; pronoto, que junto com a cabeça apresentam-se cobertos com uma pálida pubescência amarela, com duas depressões látero-anteriores; esterno e urosternitos predominantemente negros. Tégminas com uma listra costal estendendo-se desde a base até o ápice (perto da base e além da metade não atingindo a margem costal), outra central e longitudinal, começando perto da metade e estendendo-se até o ápice, e uma listra claval iniciando-se no fim do terço anterior e atingindo o início do terço posterior, negras. Asas fuliginosas 
com venação escura, tornando-se vermelha na base. Coxas, trocânteres e tarsos enegrecidos; tíbias posteriores com 19 espinhos apicais; artículo basal do tarso posterior com 13 espinhos apicais, cobertos por um denso conjunto de cerdas.

Medidas: com base em onze machos e treze fêmeas.

$\mathrm{MACHOS}$

Média

Compr. total

Compr. tégmina

Larg. tégmina

Compr. pronoto

Larg. pronoto

\section{Media}

20,672

17,327

4,854

3,699

5,945
D.P.

0,725

0,616

0,216

0,161

0,169

F ÊM E A S

Média

D.P.

Material examinado: $10^{\circ}$ - P. Alegre - C. A. Trois (CAT); 1 Pelotas-?-(UEPAE); 1 o - Santa Maria-L. C. Becker; 1 \&-Estrela-A. Brackmann, 1 Q-Restinga Seca-L. D. Paul (UFSM); 1 \&-P. Alegre F. L. Widholzer, 1 ф-Taquari-?-, 10 -Torres-F. C. Buar, 1 \&-P. Alegre-D. Cruz, 2 ९९ -Porto Alegre-G. S. Carvalho (FASE); 1 ○ - Inácio, $1 \uparrow$ Oliveira, 2 ơ o" e 19 - Butignol, $10^{\circ}$ - G. S. Carvalho - todos de P. Alegre (PUC); 1 Q - Guaíba - E. Corseuil, 1 ○ P. Alegre - Albuquerque, 1 Taquari - Costa Neto (IPA); 1 ơ e 1 S Sapucaia do Sul, 1 \& - São Leopoldo, 1 o* e 1 \& - Salvador do Sul, 1 \& - P. Alegre, 1 \& - Montenegro (Pareci Novo) - todos pelo Pe. Buck (MAPA); 1 \& - P. Alegre - L. Buckup, 2 O*O - Montenegro - M. H. Galileo, 1 \% - Montenegro - E. H. Buckup

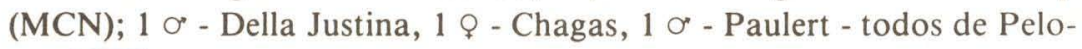
tas (UFP).

\section{Sphenoclypeana parana (Distant, 1909)}

Tomaspis parana Distant, 1909a:193; Lallemand, 1912a:96

Guarania parana; Nast, 1951b:59 (Fig. 3b); Fennah, 1968:171; Guagliumi, 1970:84.

Sphenoclypeana parana; Lallemand \& Synave, 1952a:10; Metcalf, 1961:126 (cat.); Nast, 1975:99.

Distribuição: Brasil (Paraná, Rio de Janeiro e Rio Grande do Sul), Paraguai.

\section{Caracterização segundo Distant, 1909a:193}

Cabeça é pronoto sanguíneos, com excessão da metade basal da cabeça e duas manchas sobre a área anterior do pronoto, que são negras. Escutelo, urotergitos, urosternitos, esterno e pernas negras. Posclípeo, ápice do escutelo e margem lateral do prosterno, sanguíneos. Tégminas 
com coloração e disposição das manchas negras semelhantes a $S$. consanguinea, porém estas são mais desenvolvidas e a mancha costal atinge o bordo apical.

Embora esta espécie seja citada para o Estado (Guagliumi, 1970:84), não foi encontrada no material que examinei. Creio que possa ter havido engano na determinação da espécie, já que $S$. consanguinea e $S$. parana são muito próximas, diferindo no tamanho da tégmina, que nesta espécie tem o comprimento superior a três vezes a sua largura; na coloração da cabeça e pronoto os quais não são inteiramente sanguíneos; e ainda na cor do escutelo e pernas, que são negros.

Porém, para que se possa ter certeza, seria necessário examinar o mesmo material que originou a referência ou, na sua inexistência, proceder uma coleta mais intensa e sistemática, a fim de tentar localizar exemplares da referida espécie.

\section{REFERÊNCIAS}

Carvalho, G. S., 1981. Cercopideos no Rio Grande do Sul, Brasil (Hom., Auchenorhyncha). Dissertação de Mestrado, PUC - RS de P. Alegre, RS, Brasil, 100 pp.

Fennah, R. G., 1968. Revisionary notes on the New World genera of Cercopid frog hoppers (Homoptera - Cercopoidea). Bull. ent. Res., London 58 (1):165-190.

Guagliumi, P., 1970. As cigarrinhas dos canaviais (Hom. Cercopidae) no Brasil. (VI contribuição) - A nova nomenclatura e distribuição das espécies mais importantes. Brasil Açucareiro, Rio de Janeiro 76 (1):75-90.

Metcalf, Z. P., 1961. General Catalogue of the Homoptera. Raleigh, N. C., North Carolina State College. Fasc. VII, part. 2, - Cercopidae, $616 \mathrm{pp}$.

Nast, J., 1975. Further studies on Neotropical Cercopidae (Homoptera). Annls. Zool., Warsz. 33:93-101. 